\title{
Maternal Anthropometrics in Pregnancy Are Associated with Left Ventricular Mass in Infancy. The Generation R Study
}

\author{
J. J. MIRANDA GEELHOED, LENNIE VAN OSCH-GEVERS, BERO O. VERBURG, ERIC A. P. STEEGERS, ALBERT HOFMAN, \\ WILLEM HELBING, JACQUELINE C. M. WITTEMAN, AND VINCENT W. V. JADDOE
}

The Generation R Study Group [J.J.M.G., B.O.V., V.W.V.J.], Department of Epidemiology [J.J.M.G., B.O.V., A.H., J.C.M.W., V.W.V.J.], Department of Pediatrics [L.O.-G., W.H., V.W.V.J.], Department of Obstetrics and Gynaecology [E.A.P.S.], Erasmus Medical Center, 3000 CA Rotterdam, The Netherlands

\begin{abstract}
Pregnancy and early life factors may permanently affect left ventricular growth and development in the offspring. The aim of this study was to examine the associations of maternal anthropometrics during pregnancy with left ventricular mass (LVM) in infancy. This study was embedded in the Generation R Study, a population-based prospective cohort study from fetal life onwards. Maternal anthropometrics were obtained in early (gestational age $<18 \mathrm{wk}$ ), mid- (gestational age 18-25 wk), and late (gestational age $>25$ wk) pregnancy. Echocardiographic follow-up measurements were performed in 791 infants aged $6 \mathrm{wk}$ and 6 mo. We found no associations of maternal height, weight, or body mass index (BMI) measured in early, mid-, and late pregnancy with longitudinally measured left ventricular mass (LVM) from $6 \mathrm{wk}$ to 6 mo. Maternal weight gain until late pregnancy was associated with an increased growth of LVM from 6 wk to 6 mo [difference $0.46 \mathrm{~g}$ per week for the highest tertile of weight gain compared with the lowest tertile ( $p$ value $<0.05)]$. We concluded that maternal weight gain until late pregnancy is associated with larger LVM at the age of $6 \mathrm{mo}$, suggesting that maternal health status during pregnancy may have permanent consequences for LVM in their children. Further studies are needed to identify the underlying causal mechanisms and the long-term consequences. (Pediatr Res 63: 62-66, 2008)
\end{abstract}

$\mathrm{L}$ eft ventricular hypertrophy is a strong and independent risk factor of cardiovascular morbidity and mortality (1). Left ventricular mass (LVM) tracks from childhood to adulthood, meaning that, relative to body size, the size of the heart of a subject remains in a given rank order over time compared with other subjects (2). The human heart has its highest growth rates in fetal and early postnatal life (3). After this period, increase in cardiac muscle mass is mainly due to enlargement of preexisting cells (4). This rapid growth in fetal

Received April 6, 2007; accepted August 17, 2007

Correspondence: Vincent W. V. Jaddoe, M.D., Ph.D., The Generation R Study Group (AE-006), Erasmus Medical Center, PO Box 2040, 3000 CA Rotterdam, The Netherlands; e-mail: v.jaddoe@erasmusmc.nl

The first phase of the Generation R Study is made possible by financial support from the Erasmus Medical Center, Rotterdam, the Erasmus University Rotterdam and the Netherlands Organization for Health Research and Development (ZonMw). The study described in this paper was made possible by an additional grant from the Netherlands Organization for Health Research and Development (ZonMw, Grant No. 2100.0074).

The Generation R Study is conducted by the Erasmus Medical Center in close collaboration with the School of Law and Faculty of Social Sciences of the Erasmus University Rotterdam, the Municipal Health Service Rotterdam area, Rotterdam, the Rotterdam Homecare Foundation, Rotterdam and the Stichting Trombosedienst \& Artsenlaboratorium Rijnmond (STAR), Rotterdam. and early postnatal life suggests that early life factors may permanently affect cardiac growth and development (3).

The developmental origins of health and disease hypothesis postulates that adverse environmental exposures in fetal and early postnatal life lead to adaptations that permanently program the fetus' structure, physiology, and metabolism $(5,6)$. This hypothesis is supported by both animal studies and epidemiologic studies, which have consistently shown associations of fetal and early postnatal growth characteristics with development of cardiovascular disease and its risk factors $(7,8)$. However, fetal cardiovascular adaptations may be present without overt changes in fetal and early postnatal growth characteristics. Maternal anthropometrics during pregnancy are related to their nutritional and health status and thereby to fetal environmental exposures $(9,10)$. Several studies have shown that maternal anthropometric factors such as body mass index (BMI), weight gain during pregnancy, and insulin resistance are associated with fetal growth characteristics and adverse pregnancy outcomes (11-15). Recently, it has also been suggested that both maternal gestational diabetes and macrosomia in children of mothers without overt gestational diabetes were associated with newborn LVM (16). Thus, maternal nutritional and health status during pregnancy may lead to an adverse fetal environment and might affect cardiac growth and development.

We hypothesized that maternal anthropometrics during pregnancy affects cardiac growth and development in early postnatal life. Therefore, we examined in a population-based, prospective cohort study whether maternal height, weight, and BMI in various periods of pregnancy and maternal weight gain during pregnancy are associated with LVM growth between 6 wk and 6 mo.

\section{PATIENTS AND METHODS}

Design. This study was embedded in the Generation R Study, a population-based prospective cohort study from fetal life until young adulthood. This study is designed to identify early environmental and genetic determinants of growth, development, and health from fetal life until young adulthood and has been described previously in detail $(17,18)$. In total, the cohort includes 9778 mothers and their children living in Rotterdam, the Netherlands. A vast majority of mothers were enrolled in the first trimester of pregnancy (18). Assessments in pregnancy included physical examinations, fetal ultrasounds, biologic samples, and questionnaires and were planned in early (gestational age $<18$ wk), mid- (gestational age 18-25 wk), and late pregnancy (gesta- 
tional age $>25$ wk) to collect information about fetal growth and its main determinants. In this cohort, additional, more-detailed assessments of fetal and postnatal growth and development are conducted in a subgroup of 1232 Dutch mothers and their children from late pregnancy. This subgroup is referred to as the Generation $\mathrm{R}$ Focus cohort. This subgroup is ethnic homogeneous to exclude possible confounding or effect modification by ethnicity. Dutch ethnicity was defined as having two parents and four grandparents born in the Netherlands (18). Between February 2003 and April 2005, all mothers participating in the Generation R Study and pregnant of children who met this criterion were approached for these additional measurements in late pregnancy (gestational age $30 \mathrm{wk}$ ). No other exclusion criteria were used. Of all approached women, $80 \%$ agreed to participate in this subgroup study. In this subgroup, follow-up postnatal echocardiograms were performed in infants at the ages of $6 \mathrm{wk}$ and 6 mo. The study has been approved by the Medical Ethics Committee of the Erasmus Medical Center, Rotterdam. Written informed consent was obtained from all participants.

Population for analysis. In total, 1232 women were enrolled in the Generation R Focus Study at a gestational age of $30 \mathrm{wk}$. The present analysis was limited to singleton live births $(n=1,215)$. Twin pregnancies $(n=15)$ and pregnancies leading to intrauterine or perinatal death $(n=2)$ were excluded from the analysis. None of the children in this analysis had congenital heart disease. Of the singleton live births, $76 \%(n=923)$ participated in the postnatal assessment at $6 \mathrm{wk}$ of age and $74 \%(n=903)$ participated in the postnatal assessments at 6 mo of age. Echocardiograms were performed in $85 \%(n=791)$ of these infants at $6 \mathrm{wk}$ and in $87 \%(n=785)$ of these infants at 6 mo of age. Missing echocardiograms were mainly due to crying behavior or unavailability of equipment or echocardiographer.

Maternal anthropometrics. Maternal anthropometrics were measured in one of the research centers at the visits in early (gestational age $<18 \mathrm{wk}$ ), mid- (gestational age 18-25 wk), and late pregnancy (gestational age $>25$ wk). We measured weight $(\mathrm{kg})$ and height $(\mathrm{cm})$ and we calculated maternal body mass index $\left(\mathrm{kg} / \mathrm{m}^{2}\right)$ for each pregnancy period. The gestational age medians (95\% range) for these assessments were 12.6 (9.6-16.9) wk, 20.4 (18.6-22.5) wk, and $30.2(28.5-32.5) \mathrm{wk}$, respectively. Information about maternal weight just before pregnancy was obtained from questionnaires. Self-reported weight just before pregnancy was highly correlated to measured weight at intake $(r=0.97, p$ value $<0.01)$. Weight gain was defined as the difference between weight before pregnancy and in late pregnancy (gestational age $30 \mathrm{wk}$ ). This is a measure of first two-trimester weight gain.

Left cardiac structure. Two-dimensional M-mode was performed on Kretz Voluson 530D equipment in the children at $6 \mathrm{wk}$ and $6 \mathrm{mo}$ of age. The examination was carried out in a quiet room with the baby quietly awake in a supine position. One echocardiographer performed the vast majority $(86 \%)$ of these measurements. Two other echocardiographers performed the other measurements. In a parasternal long-axis view, left ventricular end diastolic diameter (LVEDD), interventricular septal thickness (IVST), and left ventricular posterior wall thickness (LVPWT) were measured using methods recommended by the American Society of Echocardiography (19). LVM was computed by use of the formula derived by Devereux et al. (20):

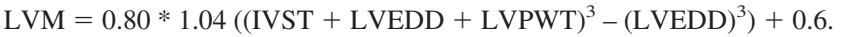

The intraobserver intraclass correlation coefficients for the echocardiographic measurements in the present study were similar as previously demonstrated in large scale multicenter studies in young children $(21,22)$.

Covariates. All anthropometrics in the infants were measured without clothes at the same visits as the echocardiograms at $6 \mathrm{wk}$ and 6 mo of age. Weight was measured to the nearest gram using electronic scales. Length was measured in supine position to the nearest millimeter using a neonatometer. Birth weight, date of birth, and gender were obtained from midwife and hospital registries.

Data analysis. Associations of maternal anthropometrics with repeatedly measured LVM at $6 \mathrm{wk}$ and 6 mo of age were first assessed using repeated measures regression analysis using the Proc Mixed module of SAS (23). This is a regression technique that takes the correlation of multiple measurements within one subject into account and is used to examine response trends over time (23). Maternal anthropometrics included weight and body mass index measured in early, mid-, and late pregnancy and weight gain during pregnancy. Based on tertiles of weight gain until late pregnancy within our study population, we constructed three categories for increase in weight $(<6.5 \mathrm{~kg}$, $6.5-9.0 \mathrm{~kg}$, and $>9.0 \mathrm{~kg}$ ). Weight gain during pregnancy was included in the model as an interaction term with age $(p$ value $<0.05)$. This model enables us to assess both the time independent and time dependent effects of weight gain on LVM. The model can be written as:

$\mathrm{LVM}=\beta_{0}+\beta_{1} *$ increase in weight $+\beta_{2} *$ age $+\beta_{3} *$ increase in weight * age.
In this model, the term including " $\beta_{0}+\beta_{1}$ " reflects the intercept and the term including " $\beta_{2}$ " reflects the slope of growth in LVM per week. The term including " $\beta_{3}$ " reflects the differences in growth of LVM between the different categories of increase in weight. First, we examined the association of maternal weight, BMI, and weight gain in pregnancy with LVM in the offspring adjusted for gender (Model I). All models were additionally adjusted for current weight and current length of the children (Model II). Models with maternal weight gain as independent variable were additionally adjusted for maternal weight and height just before pregnancy (Model II).

Subsequently, we performed multiple linear regression models to study the associations of maternal anthropometrics with LVM at the ages of 6 wk and 6 mo separately. These models were first adjusted for gender and age at the visit (Model A) and additionally for current weight and current length of the children (Model B). All measures of association are presented with their $95 \%$ confidence intervals (CI). Statistical analyses were performed using the Statistical Analysis System version 8.2 (SAS, Stata Corporation, College Station, TX), including the Proc Mixed module for unbalanced repeated measurements and the Statistical Package of Social Sciences version 11.0 for Windows (SPSS Inc, Chicago, IL).

\section{RESULTS}

Characteristics of infants who participated in the postnatal echocardiogram studies and their mothers are presented in Table 1 . The percentage of boys was $52 \%$. Birth weight was larger in boys than in girls. The overall median age in infants at their $6 \mathrm{wk}$ visit was 6.4 (95\% range: $4.4-12.5$ ) wk and at their 6 mo visit 27.3 (95\% range: $23.7-35.6$ ) weeks. Weight, length, and LVM were somewhat smaller in girls than in boys. Infants who had a postnatal echocardiogram $(n=791)$ did not differ from the postnatal nonresponders $(n=424)$ in maternal weight [difference $0.6(95 \% \mathrm{CI}:-1.1,2.3) \mathrm{kg}$ ] and maternal BMI [difference $0.2(95 \% \mathrm{CI}:-0.4,0.7) \mathrm{kg} / \mathrm{m}^{2}$ ] just before pregnancy. Figure 1 shows the correlations between infant characteristics and LVM.

The associations between maternal anthropometrics during pregnancy and longitudinal measured LVM in infancy are presented in Table 2. No associations were found of maternal weight and BMI in early, mid-, and late pregnancy with growth of LVM. Compared with mothers with the lowest increase in weight during pregnancy, growth of LVM was 0.28 (95\% CI: $-0.17,0.72) \mathrm{g} / \mathrm{wk}$ lower in mothers with moderate increase in weight during pregnancy and 0.46 (95\% CI: 0.02 , $0.90) \mathrm{g} / \mathrm{wk}$ higher in mothers with the highest increase in weight during pregnancy.

Table 3 gives the associations between maternal weight gain during pregnancy with LVM at the ages of $6 \mathrm{wk}$ and $6 \mathrm{mo}$ separately. We did not find an association of maternal weight gain during pregnancy with LVM at 6 wk of age (Table 3). However, weight gain during pregnancy was positively associated with postnatal LVM at the age of 6 mo. For each $\mathrm{kg}$ increase in weight during pregnancy, LVM at the age of $6 \mathrm{mo}$ increased by 0.08 (95\% CI: 0.02, 0.15) grams. This means an increase of $0.47 \%$. The associations did not materially change after adjustment for maternal weight and height just before pregnancy, and gender, age, weight and length of the child (Table 3).

\section{DISCUSSION}

Our study demonstrates for the first time that higher maternal weight gain during pregnancy is associated with a higher increase in growth of LVM during the first 6 mo of 
Table 1. Subject characteristics

\begin{tabular}{|c|c|c|c|}
\hline & Boys $(n=413)$ & Girls $(n=378)$ & $p$ Value \\
\hline \multicolumn{4}{|l|}{ Pregnancy and birth characteristics } \\
\hline Maternal age (y) & $31.8(4.0)$ & $32.3(3.8)$ & 0.09 \\
\hline Maternal height $(\mathrm{cm})$ & $170.9(6.0)$ & $170.9(6.8)$ & 0.66 \\
\hline Maternal weight before pregnancy (kg) & $71.0(13.2)$ & $71.9(12.5)$ & 0.20 \\
\hline Maternal BMI before pregnancy $\left(\mathrm{kg} / \mathrm{m}^{2}\right)$ & $24.3(4.3)$ & $24.6(4.2)$ & 0.24 \\
\hline Maternal weight in late pregnancy $\left(\mathrm{kg} / \mathrm{m}^{2}\right)$ & $78.9(12.8)$ & $79.7(12.6)$ & 0.38 \\
\hline Birth weight $(\mathrm{g})$ & $3559(535)$ & $3463(542)$ & 0.05 \\
\hline Gestational age (wk) & $39.9(35.3-42.1)$ & $40.0(35.7-42.1)$ & 0.79 \\
\hline \multicolumn{4}{|l|}{ Postnatal characteristics visit $6 \mathrm{wk}$} \\
\hline Age at visit (wk) & $6.4(4.5-12.9)$ & $6.4(4.4-11.9)$ & 0.38 \\
\hline Weight $(\mathrm{g})$ & $5088(749)$ & $4758(627)$ & $<0.01$ \\
\hline Length $(\mathrm{cm})$ & $58(3)$ & $56(3)$ & $<0.01$ \\
\hline $\operatorname{LVM}(\mathrm{g})$ & $13.8(2.7)$ & $12.7(2.5)$ & $<0.01$ \\
\hline \multicolumn{4}{|l|}{ Postnatal characteristics visit $6 \mathrm{mo}$} \\
\hline Age at visit (wk) & $27.4(23.9-35.0)$ & $27.3(23.6-36.1)$ & 0.67 \\
\hline Weight $(\mathrm{g})$ & $8191(840)$ & $7628(812)$ & $<0.01$ \\
\hline Length $(\mathrm{cm})$ & $70(3)$ & $68(3)$ & $<0.01$ \\
\hline $\operatorname{LVM}(\mathrm{g})$ & $18.0(3.7)$ & $16.4(3.5)$ & $<0.01$ \\
\hline
\end{tabular}

Values are means (SD) or medians (95\% range) for variables with skewed distribution.

Of the total group, data were missing on maternal weight before pregnancy $(n=140)$, maternal BMI before pregnancy $(n=140)$, weight 6 wk $(n=14)$, length $6 \mathrm{wk}(n=18)$, weight $6 \mathrm{mo}(n=26)$, length $6 \mathrm{mo}(n=26)$, LVM $6 \mathrm{wk}(n=102)$, and LVM 6 mo $(n=120)$. $p$ Values were based on unpaired sample $t$ test examining the differences between boys and girls.

life. These findings suggest that maternal anthropometrics during pregnancy may have consequences for LVM in the offspring.

Methodological considerations. Postnatal follow-up echocardiograms were successfully obtained in $65 \%$ of all singleton live births of the mothers participating in the Generation $\mathrm{R}$ Focus Study. Maternal anthropometrics in pregnancy were similar between infants who had a postnatal echocardiogram and the postnatal nonresponders. The observed effect estimates would be biased if the associations of maternal anthropometrics with LVM differ between those included and not included in the present analyses. This seems unlikely. The missing values of LVM among infants who did participate in postnatal visits were mainly due to crying behavior or unavailability of equipment or echocardiographer and are unlikely to lead to biased results.

Weight gain was partly based on self-reported weights, which is known to introduce measurements error. Based on an assessment of validity of self-reported weight in the US Third National Health System, women in this age group may systematically underestimate their weights (24). Inasmuch as self-reported weight just before pregnancy was highly correlated $(r=0.97)$ to measured weight at intake, we do not think that this would lead to biased results.
A
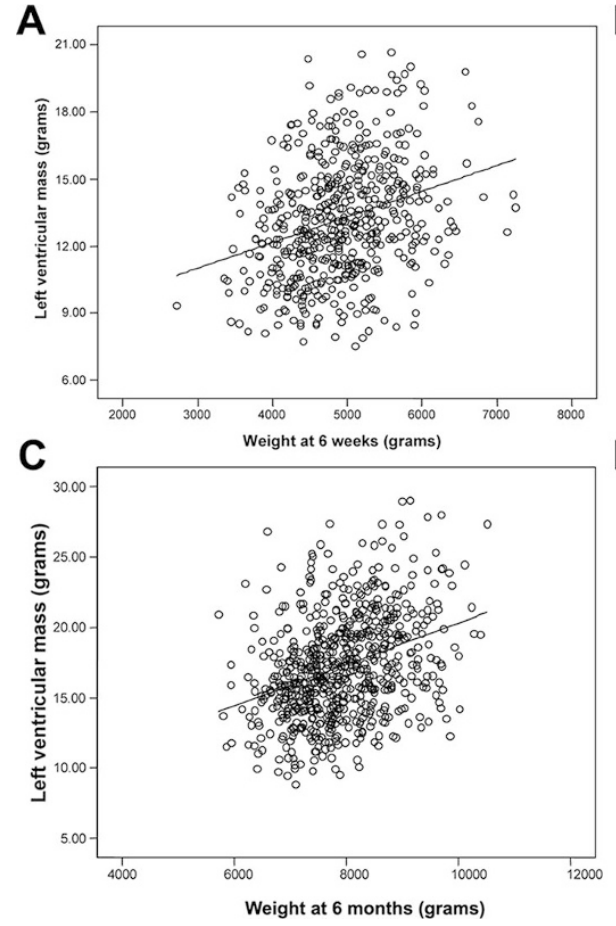

B

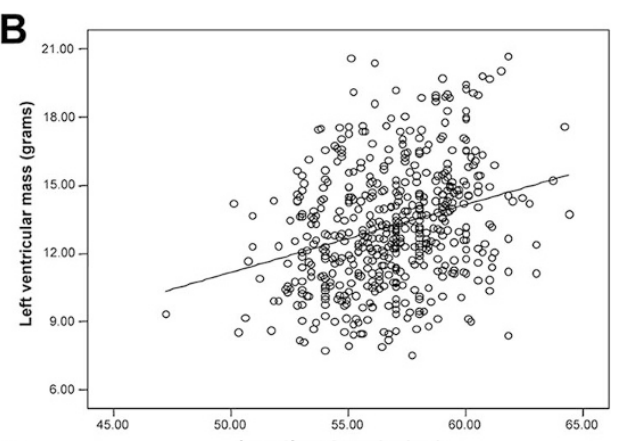

D

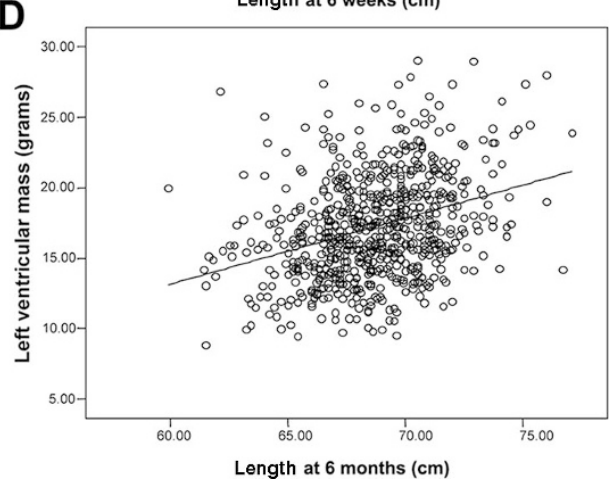

Figure 1. Correlations of individual measurements of infant weight and length with LVM at the ages of $6 \mathrm{wk}$ and $6 \mathrm{mo}$. (A) Correlation weight and LVM at the age of $6 \mathrm{wk}, r=0.30$, $p$ value $<0.01$. (B) Correlation length and LVM at the age of $6 \mathrm{wk}, r=0.29, p$ value $<0.01$. (C) Correlation weight and LVM at the age of $6 \mathrm{mo}, r=0.35, p$ value $<0.01$. (D) Correlation length and LVM at the age of 6 mo, $r=0.33, p$ value $<0.01$. 
Table 2. Maternal anthropometrics and tertiles of weight gain in pregnancy and longitudinal measured growth in LVM

\begin{tabular}{ccc}
\hline & \multicolumn{2}{c}{ Change in LVM $(\mathrm{g} / \mathrm{wk})$} \\
\cline { 2 - 3 } & Model I & Model II \\
\hline Early pregnancy & & \\
Height $(\mathrm{cm})$ & $0.06(0.01,0.09)^{*}$ & $0.01(-0.03,0.06)$ \\
Weight $(\mathrm{kg})$ & $0.01(-0.01,0.03)$ & $0.01(-0.01,0.02)$ \\
Body mass index & $0.03(-0.02,0.07)$ & $0.02(-0.02,0.06)$ \\
$\quad\left(\mathrm{kg} / \mathrm{m}^{2}\right)$ & & \\
Mid-pregnancy & & \\
Weight $(\mathrm{kg})$ & $0.02(0.01,0.03)^{* *}$ & $0.01(-0.01,0.02)$ \\
Body mass index & $0.04(-0.01,0.08)$ & $0.03(-0.01,0.07)$ \\
$\left(\mathrm{kg} / \mathrm{m}^{2}\right)$ & & \\
Late pregnancy & & $0.01(-0.01,0.03)$ \\
Weight $(\mathrm{kg})$ & $0.02(0.00,0.05)^{* *}$ & $0.03(-0.01,0.08)$ \\
Body mass index & $0.04(-0.01,0.09)$ & \\
$\left(\mathrm{kg} / \mathrm{m}^{2}\right)$ & & Reference \\
Weight gain $(\mathrm{kg})$ & Reference & $-0.28(-0.72,0.17)$ \\
$<6.5$ & $-0.22(-0.68,0.24)$ & $0.46(0.02,0.90)^{* *}$ \\
$6.5-9.0$ & $0.62(0.17,1.08)^{*}$ & \\
$\geq 9.0$ &
\end{tabular}

Values are regression coefficients (95\% confidence interval) and reflect the difference in growth of LVM for the different categories of maternal anthropometrics and weight gain in pregnancy. Model I: adjusted for gender; Model II: additionally adjusted for current weight and current length. Models with weight gain as independent variable are additionally adjusted for maternal weight and height just before pregnancy.

$* p<0.01,{ }^{* *} p<0.05$.

Table 3. Maternal weight gain during pregnancy and LVM at 6 wk and 6 mo

\begin{tabular}{cc}
\hline \multicolumn{2}{c}{ Difference in LVM 6 wk $(\mathrm{g})$} \\
\cline { 2 - 3 } Model A & Model B \\
\hline
\end{tabular}

$\begin{array}{llll}\text { Weight gain }(\mathrm{kg}) & 0.06(-0.01,0.12) & 0.45 \% & 0.03(-0.03,0.09)\end{array}$

Difference in LVM 6 mo $(\mathrm{g})$

Model A Model B

$\begin{array}{lllll}\text { Weight gain }(\mathrm{kg}) & 0.11(0.04,0.18) * & 0.64 \% & 0.08(0.02,0.15) * & 0.47 \%\end{array}$

Values are regression coefficients (95\% confidence interval) and reflect the difference in LVM per unit weight gain in maternal weight. Model A: adjusted for maternal weight and height just before pregnancy, age and gender; Model B: additionally adjusted for current weight and current length.

$* p<0.01$.

In the present analysis, we defined maternal weight gain as the difference between weight in late pregnancy and weight just before pregnancy. In fact, this is the increase in weight in the first two trimesters of pregnancy. Ideally, weight gain during pregnancy should be defined as the difference between the highest weight in pregnancy and the weight just before pregnancy. Since the largest differences in maternal weight gain during pregnancy are expected to appear in late pregnancy, our associations between weight gain and LVM may be underestimated.

Maternal anthropometrics and LVM. No associations were found of maternal weight and BMI in early, mid-, and late pregnancy with LVM in infancy. We found that mothers who increase more in weight during pregnancy have children with an increased growth of the LVM in the first $6 \mathrm{mo}$, resulting in larger LVM at the age of 6 mo. These associations were independent of maternal weight just before pregnancy.

Anthropometrics during pregnancy reflect maternal nutritional and health status and may be measures of fetal environmental exposures (10). Increased maternal weight gain during pregnancy may be caused by several factors including nutrition, obesity, fluid retention, and lower physical activity levels (25). Furthermore, increased maternal weight gain during pregnancy is associated with various pregnancy complications including insulin resistance, gestational diabetes, and pregnancy-induced hypertension. Therefore, several underlying biologic pathways may explain the associations between maternal anthropometrics in pregnancy and LVM in infancy. The usual increase in insulin resistance seen in late pregnancy is higher in mothers who show a marked increase in weight during pregnancy (26). Insulin resistance causes higher glucose levels in the mother. Since glucose passes the placenta to the child, fetal insulin production will be increased. Insulin is the main fetal growth factor and may stimulate fetal body and heart growth (27). Offspring of mothers with gestational diabetes have increased cardiac sizes in the neonatal phase (16). However, this larger cardiac size is usually not present anymore at the age of 6 mo (28). In our study, data on subclinical insulin resistance or increased glucose levels during pregnancy were not available. The number of pregnant women with doctor-diagnosed gestational diabetes in our study was too small $(n=45)$ to assess the effect on LVM. Another biologic pathway may directly be related to the nutrition intake of the mother during pregnancy $(29,30)$. Excessive fetal exposure to energy sources may lead to rapid growth and cardiac enlargement. Further studies, in which measures of insulin resistance such as insulin, glucose, or HbA1c levels and maternal nutrition in pregnancy have been measured, are needed to identify the underlying causal pathways.

The associations could also be explained by postnatal factors related to postnatal growth, nutrition, blood pressure development, and genetic susceptibility (31-33). We showed that the effect of weight gain on LVM was still present after adjustment for current weight. Thus, we do not think that postnatal anthropometrics explain the associations. However, previous studies showed that in adolescents, increase in BMI from early childhood, rather than current BMI is associated with LVM $(32,33)$. Thus, postnatal growth patterns or their determinants, which are also associated with a maternal weight gain in pregnancy, may explain part of these associations. Further follow up studies in our and other cohorts may reveal these underlying mechanisms.

The effect estimates shown in our study are unlikely to be of any clinical significance in infancy. However, our results suggest an etiological role of maternal anthropometrics during pregnancy in LVM development. Increased LVM may precede the development of left ventricular hypertrophy and increased blood pressure. Left ventricular hypertrophy and hypertension are risk factors for cardiovascular morbidity and mortality (1). Whether and to what extent the effects of maternal anthropometrics on LVM persists in childhood and in adulthood needs to be further studied. 
Study implications. Our findings demonstrated that maternal anthropometrics, as measure of fetal environment, are associated with LVM in infancy. The effect sizes seem to be too small for clinical implications. However, these results are of interest from a developmental perspective and add new support for the developmental origins of health and disease hypothesis. Further studies examining the underlying biologic pathways and the long-term consequences are needed.

Acknowledgments. The authors thank the general practitioners, hospitals, midwives and pharmacies in Rotterdam for their contribution to this study.

\section{REFERENCES}

1. Levy D, Garrison RJ, Savage DD, Kannel WB, Castelli WP 1990 Prognostic implications of echocardiographically determined left ventricular mass in the Framingham Heart Study. N Engl J Med 322:1561-1566

2. Schieken RM, Schwartz PF, Goble MM 1998 Tracking of left ventricular mass in children: race and sex comparisons: the MCV Twin Study. Medical College of Virginia. Circulation 97:1901-1906

3. Ishii A, Tatsunami S, Satoh I, Honma T, Hamada H, Yago N 1990 Growth dynamics of the heart from perinatal period to childhood. J Perinat Med 18:459-463

4. Claycomb WC 1977 Cardiac-muscle hypertrophy. Differentiation and growth of the heart cell during development. Biochem J 168:599-601

5. Barker DJ 1995 Fetal origins of coronary heart disease. BMJ 311:171-174

6. Bateson P, Barker D, Clutton-Brock T, Deb D, D’Udine B, Foley RA, Gluckman P, Godfrey K, Kirkwood T, Lahr MM, McNamara J, Metcalfe NB, Monaghan P, Spencer HG, Sultan SE 2004 Developmental plasticity and human health. Nature 430:419-421

7. Frankel S, Elwood P, Sweetnam P, Yarnell J, Smith GD 1996 Birthweight, bodymass index in middle age, and incident coronary heart disease. Lancet 348:14781480

8. Curhan GC, Willett WC, Rimm EB, Spiegelman D, Ascherio AL, Stampfer MJ 1996 Birth weight and adult hypertension, diabetes mellitus, and obesity in US men. Circulation 94:3246-3250

9. Siega-Riz AM, Adair LS 1993 Biological determinants of pregnancy weight gain in a Filipino population. Am J Clin Nutr 57:365-372

10. Bergmann MM, Flag EW, Miracle-McMahill HL, Boeing H 1997 Energy intake and net weight gain in pregnant women according to body mass index (BMI) status. Int J Obes Relat Metab Disord 21:1010-1017

11. Kabiru W, Raynor BD 2004 Obstetric outcomes associated with increase in BMI category during pregnancy. Am J Obstet Gynecol 191:928-932

12. Sermer M, Naylor CD, Gare DJ, Kenshole AB, Ritchie JW, Farine D, Cohen HR, McArthur K, Holzapfel S, Biringer A 1995 Impact of increasing carbohydrate intolerance on maternal-fetal outcomes in 3637 women without gestational diabetes. The Toronto Tri-Hospital Gestational Diabetes Project. Am J Obstet Gynecol 173:146-156

13. Edwards LE, Hellerstedt WL, Alton IR, Story M, Himes JH 1996 Pregnancy complications and birth outcomes in obese and normal-weight women: effects of gestational weight change. Obstet Gynecol 87:389-394

14. Sebire NJ, Jolly M, Harris JP, Wadsworth J, Joffe M, Beard RW, Regan L, Robinson S 2001 Maternal obesity and pregnancy outcome: a study of 287,213 pregnancies in London. Int J Obes Relat Metab Disord 25:1175-1182
15. Jensen DM, Damm P, Sorensen B, Molsted-Pedersen L, Westergaard JG, Ovesen P, Beck-Nielsen H 2003 Pregnancy outcome and prepregnancy body mass index in 2459 glucose-tolerant Danish women. Am J Obstet Gynecol 189:239-244

16. Akcakus M, Koklu E, Baykan A, Yikilmaz A, Coskun A, Gunes T, Kurtoglu S, Narin N 2007 Macrosomic newborns of diabetic mothers are associated with increased aortic intima-media thickness and lipid concentrations. Horm Res 67:277283

17. Hofman A, Jaddoe VW, Mackenbach JP, Moll HA, Snijders RF, Steegers EA, Verhulst FC, Witteman JC, Buller HA 2004 Growth, development and health from early fetal life until young adulthood: the Generation R Study. Paediatr Perinat Epidemiol 18:61-72

18. Jaddoe VW, Mackenbach JP, Moll HA, Steegers EA, Tiemeier H, Verhulst FC, Witteman JC, Hofman A 2006 The Generation R Study: design and cohort profile. Eur J Epidemiol 21:475-484

19. Schiller NB, Shah PM, Crawford M, DeMaria A, Devereux R, Feigenbaum H, Gutgesell H, Reichek N, Sahn D, Schnittger I 1989 Recommendations for quantitation of the left ventricle by two-dimensional echocardiography. American Society of Echocardiography Committee on Standards, Subcommittee on Quantitation of Two-Dimensional Echocardiograms. J Am Soc Echocardiogr 2:358-367

20. Devereux RB, Alonso DR, Lutas EM, Gottlieb GJ, Campo E, Sachs I, Reichek N 1986 Echocardiographic assessment of left ventricular hypertrophy: comparison to necropsy findings. Am J Cardiol 57:450-458

21. Lipshultz SE, Easley KA, Orav EJ, Kaplan S, Starc TJ, Bricker JT, Lai WW, Moodie DS, Sopko G, Schluchter MD, Colan SD 2001 Reliability of multicenter pediatric echocardiographic measurements of left ventricular structure and function: the prospective $\mathrm{P}(2) \mathrm{C}(2)$ HIV study. Circulation 104:310-316

22. Rivenes SM, Colan SD, Easley KA, Kaplan S, Jenkins KJ, Khan MN, Lai WW, Lipshultz SE, Moodie DS, Starc TJ, Sopko G, Zhang W, Bricker JT 2003 Usefulness of the pediatric electrocardiogram in detecting left ventricular hypertrophy: results from the Prospective Pediatric Pulmonary and Cardiovascular Complications of Vertically Transmitted HIV Infection (P2C2 HIV) multicenter study. Am Heart J 145:716-723

23. Littell RC, Henry PR, Ammerman CB 1998 Statistical analysis of repeated measures data using SAS procedures. J Anim Sci 76:1216-1231

24. Villanueva EV 2001 The validity of self-reported weight in US adults: a population based cross-sectional study. BMC Public Health 1:11

25. McArdle HJ, Andersen HS, Jones H, Gambling L 2006 Fetal programming: causes and consequences as revealed by studies of dietary manipulation in rats-a review. Placenta 27:S56-S60

26. King JC 2006 Maternal obesity, metabolism, and pregnancy outcomes. Annu Rev Nutr 26:271-291

27. Fowden AL 1989 The role of insulin in prenatal growth. J Dev Physiol 12:173-182

28. Weintrob N, Karp M, Hod M 1996 Short- and long-range complications in offspring of diabetic mothers. J Diabetes Complications 10:294-301

29. Olafsdottir AS, Skuladottir GV, Thorsdottir I, Hauksson A, Steingrimsdottir L 2006 Maternal diet in early and late pregnancy in relation to weight gain. Int J Obes (Lond) 30:492-499

30. Roseboom TJ, van der Meulen JH, Osmond C, Barker DJ, Ravelli AC, SchroederTanka JM, van Montfrans GA, Michels RP, Bleken OP 2000 Coronary heart disease after prenatal exposure to the Dutch famine, 1944-45. Heart 84:595-598

31. Urbina EM, Gidding SS, Bao W, Pickoff AS, Berdusis K, Berenson GS 1995 Effect of body size, ponderosity, and blood pressure on left ventricular growth in children and young adults in the Bogalusa Heart Study. Circulation 91:2400-2406

32. Li X, Ulusoy E, Chen W, Srinivasan SR, Berenson GS 2004 Childhood adiposity as a predictor of cardiac mass in adulthood: the Bogalusa Heart Study. Circulation 110:3488-3492

33. Sivanandam S, Sinaiko AR, Jacobs DR, Jr. Steffen L, Moran A, Steinberger J 2006 Relation of increase in adiposity to increase in left ventricular mass from childhood to young adulthood. Am J Cardiol 98:411-415 